\title{
Categorization time as independent of the number of condition-action rules
}

\author{
IN-MAO LIU \\ The Chinese University of Hong Kong, Shatin, N.T., Hong Kong \\ and National Taiwan University, Taipei, Taiwan
}

\begin{abstract}
A list of item pairs was presented one pair at a time. The subject's task was to respond to each pair by pressing the left or right key according to condition-action rules such as "If an English letter protruding upward or downward appears on the left (or right) side, then press the left (or right) key," "If two English capital letters in alphabetical order appear on the left (or right), then press the left (or right) key," etc. With this procedure, the number of rules does not covary with the number of responses. It was found, in Experiment 1, that the number of highly compatible rules in a list had no effect on the time of condition categorization. Experiments 2 and 3 supported the hypothesis that the lack of the rule set size effect was indeed due to the rules' being compatible. It was concluded that the bottleneck of perceptual processing occurs not at the stimulus categorization stage, but quite late at the stimulus-to-response translation stage.
\end{abstract}

The conditional statement "If $A$, then $\mathrm{R}$ " has fascinated philosophers (Kneale \& Kneale, 1962) and psychologists alike. There are at least three types of research related to the question of a conditional that have attracted the attention of psychologists.

One line of research has been conducted in the form of reaction-time (RT) experiments. For a choice RT (Donders's $b$ reaction), a conditional takes the form "If $A_{i}$ stimulus, then press $R_{i}$ key." It is understood that there are $A_{1}, A_{2}, \ldots, A_{n}$ stimuli and $R_{1}, R_{2}, \ldots, R_{n}$ keys. Largely based on Welford's (1960) conceptualization, Smith (1968) proposed essentially the following four stages in a choice RT: (1) the raw stimulus is "preprocessed" until a representation of it is formed; (2) this representation encounters memorial representations of the possible stimulus alternatives that have been transferred to a rapid-access storage system, and the stimulus is then categorized as one of the possible alternatives on the basis of certain tests or comparisons between the representation and the memorial information; (3) given this categorization, an appropriate response is selected; and (4) the execution of this response is programmed.

A second line of research is related to production systems as originally proposed by Post (1943). Production systems consisted of a set of rules, called productions, for rewriting strings of symbols and a specification of some initial strings. The notion of production systems that originated in the study of artificial intelligence corresponds to the concept of procedural knowledge in philosophy (Ryle, 1949). Procedural knowledge is knowledge about how to do something, and declarative knowledge is

This study was supported by National Science Council Grant NSC69H-03-02(03), Republic of China. Thanks are extended to Chu-hung Chao and Ching-ching Ting for their assistance. Requests for reprints should be sent to In-mao Liu, Department of Psychology, The Chinese University of Hong Kong, Shatin, N.T, Hong Kong. knowledge of facts about the world. There have been a number of recent attempts to use production systems as psychological models of procedural knowledge (e.g., Anderson, 1976; Baylor \& Gascon, 1974; Hunt \& Poltrock, 1974; Just \& Carpenter, 1980; Klahr, 1973; Newell, 1972, 1973; Newell \& Simon, 1972), although experimental studies of procedural knowledge are rarely done. A set of productions generally takes the form "If $A_{i}$ condition, then $R_{i}$ action." In the sequel, a production is uhderstood as a condition-action rule.

A third line of research originated from an attempt to understand the process of reasoning involved in the conditional "If $A$, then $\mathrm{R}$," where $\mathrm{A}$ and $\mathrm{R}$ are abstract terms or realistic statements. This line of research is concerned with propositional reasoning and is not our main concern.

The present study attempts to explore (1) the process of identifying the antecedent and (2) the process of carrying from the antecedent to the consequent of a conditional, and is therefore more related to the first two lines of research than to the third. In this respect, the terminologies of both RT experiments and production systems will be freely used, whenever no confusion arises. For the sake of easy comprehension, the term "production" is often replaced by the term "rule."

\section{Rationale and Purpose}

The process of identifying the antecedent of a conditional corresponds to Smith's first two stages, and cannot be studied simply by the procedure of "If $\mathrm{A}_{\mathrm{i}}$ stimulus, then press $\mathbf{R}_{\mathbf{i}}$ key" because the response selection stage is inevitably included. The procedure of "If $A_{i}$ stimulus, then press a common $R$ key" is also not appropriate, because it cannot be known whether the subject identifies the $A_{i}$ stimulus or the $A_{j}$ stimulus. It is suitable for studying the process of identifying a single preassigned $\mathrm{A}_{i}$, if the procedure is modified to take the form "If $A_{i}$ stimulus, then press $R$ key; if any other stimu- 
lus, then don't press R key." This is Donders's c-reaction. However, if the $A_{i}$ to be identified is preassigned, its identification or categorization process will differ from when it is simply identified from among others without being preassigned. The procedure to be proposed below obviates these difficulties.

A stimulus-categorization process is better represented as a production or condition-action rule. Examples are shown in Figure 1. On the left part of Figure 1 is a list of eight pairs of English small letters. When the pairs are presented one at a time, the subject is to press a key according to the condition-action rule: "If an English letter protruding upward or downward appears on the left (or right), then press the left (or right) key." On the right part of Figure 1 are shown two rules on the same list. Another rule is characterized by "If two English capital letters in alphabetical order appear on the left (or right), then press the left (or right) key." For a two-rule list, the subject is to act according to the two condition-action rules: "If $A_{1}\left(A_{2}\right)$, then $R_{1}\left(R_{2}\right)$; if $B_{1}\left(B_{2}\right)$, then $R_{1}\left(R_{2}\right)$." Of course, it is not known whether $A_{1}\left(A_{2}\right)$ or $B_{1}\left(B_{2}\right)$ will appear on a trial. Similarly, there may be four-rule and eight-rule lists. With this procedure, the stimuluscategorization time can be studied independently of the factor of response selection, because the latter is equated in the sense that it is used only to determine the correctness of each stimulus categorization. This procedure differs from the one-to-one stimulus-response mapping in which the number of stimuli covaries with the number of responses.
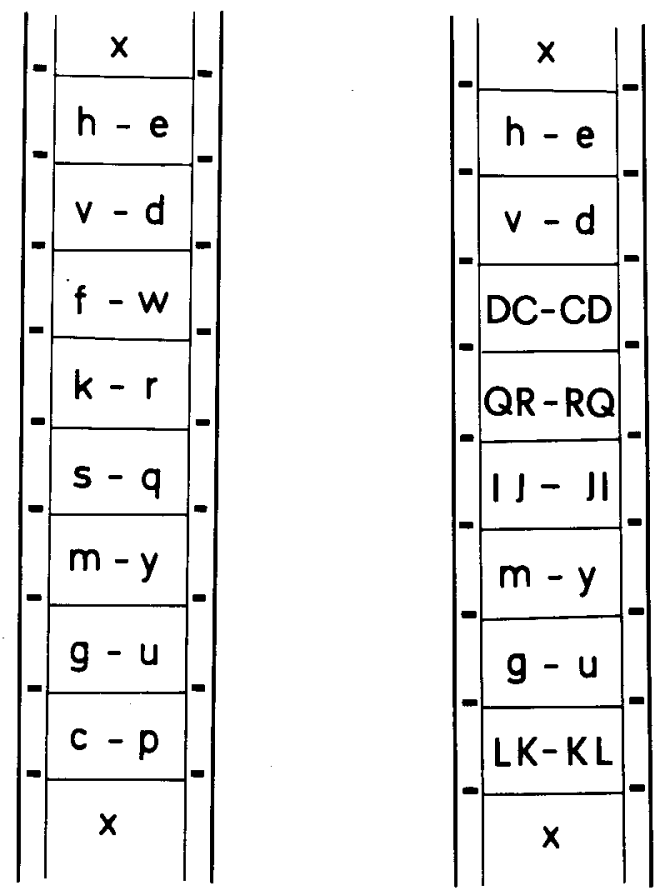

Figure 1. A list of eight condition instances for a one-rule set (left), and a list of eight condition instances for a two-rule set (right). Each list is drawn on a filmstrip, each frame containing a condition instance.
The theory of production systems would predict that $\mathrm{n}$ condition-action rules are transferred to a rapid-access storage system such as working memory. Since a rapidaccess storage system is assumed to hold only a few items (e.g., Chase \& Ericsson, 1981), the number of rules within a list should affect RT. On the other hand, there is evidence (Shiffrin, 1975, for a review) that the bottleneck of perceptual processing occurs quite late, and there is also an extensive literature on the lack of increases in RT with increasing numbers of elements in consistent visual search (e.g., Fisk \& Schneider, 1983; Schneider \& Shiffrin, 1977) or response processing (e.g., Greenwald, 1972; Greenwald \& Shulman, 1973). Therefore, there is a possibility that the rule set size effect will not be obtained if highly compatible rules are used. Experiment 1 was devised to test this conjecture.

Because the results of Experiment 1 showed the lack of increase in RT with increasing numbers of rules, Experiments 2 and 3 were conducted to see whether this finding was primarily due to the rules' being compatible.

\section{EXPERIMENT 1}

There were two important independent variables in Experiment 1 . One was number of compatible rules. The other variable was one that was manipulated through instructions as follows: Under one condition, the subject was instructed to memorize condition instances and was tested for recall after a certain number of trials. Under another condition, the subject was not required to memorize condition instances and of course was not tested for recall. The memory load produced by this manipulation should be distinguished from that of a positive set in Sternberg's (1966) search tasks and also from that of maintaining a few items in immediate memory while performing a verbal or reasoning task in Baddeley and Hitch's (1974) experiments, because in the latter the subject is only to maintain the same set of items in memory. In the present experiment, the subject was to memorize different lists of condition instances and, more importantly, to attempt to transfer these items to long-term memory. Suppose that the rule set size effect could not be obtained. Then, a natural conjecture would be that the RTs obtained in the conditions of different numbers of rules would be equally affected by requiring the subject to memorize condition instances, if rule compatibility was the sole factor for the absence of the rule set size effect.

\footnotetext{
Method

Subjects and Materials. The subjects were 12 sophomores majoring in psychology at National Taiwan University. They were paid for participating in the experiment.

There were eight types of rule used in the present experiment. Table 1 lists the type of stimulus term, a condition instance, and the rule concerned. The correct action for a given instance is also indicated in parentheses in the last column for each type of rule.

For each type of rule, eight lists of condition instances were prepared, each list consisting of eight condition instances. The eight lists of condition instances for a single type of rule will be referred to as a "one-rule set." Care was taken to equate the difficulty levels
} 
Table 1

Type of Production

\begin{tabular}{|c|c|c|c|}
\hline Production & Stimulus Items & Condition Instance & Rule \\
\hline Military & $\begin{array}{l}2 \text { military titles, one higher in rank than } \\
\text { another (in Chinese) }\end{array}$ & captain-colonel & press the key of higher rank (right key) \\
\hline Animal & $\begin{array}{l}2 \text { animal names, one larger than an- } \\
\text { other (in Chinese) }\end{array}$ & goat-rat & press the key of a larger animal (left key) \\
\hline Letter & $\begin{array}{l}2 \text { small letters, one protruding upward } \\
\text { or downward and the other neither }\end{array}$ & $h-m$ & $\begin{array}{l}\text { press the key of a protruding letter (left } \\
\text { key) }\end{array}$ \\
\hline Order & $\begin{array}{l}\text { pair of } 2 \text { capital letters, one side in al- } \\
\text { phabetical order and the other in reverse } \\
\text { order }\end{array}$ & QP-PQ & $\begin{array}{l}\text { press the key of } 2 \text { capital letters in alpha- } \\
\text { betical order (right key) }\end{array}$ \\
\hline Sameness & $\begin{array}{l}3 \text { Chinese characters, either the left }\left(C_{i}\right) \\
\text { or the right one }\left(C_{j}\right) \text { is the same as the } \\
\text { middle }\end{array}$ & $\mathrm{C}_{\mathrm{i}}-\mathrm{C}_{\mathrm{i}}-\mathrm{C}_{\mathrm{j}}$ & $\begin{array}{l}\text { press the key of a character that is the } \\
\text { same as the middle (left key) }\end{array}$ \\
\hline Phonetic & $\begin{array}{l}1 \text { Chinese phonetic symbol P and } 1 \\
\text { Chinese character C }\end{array}$ & P-C & $\begin{array}{l}\text { press the key of a phonetic symbol (left } \\
\text { key) }\end{array}$ \\
\hline Word & $\begin{array}{l}\text { 2-character Chinese word }\left(C_{1} C_{2}\right) \text { and } \\
\text { the same } 2 \text { characters in reverse order } \\
\left(C_{2} C_{1}\right)\end{array}$ & $\mathrm{C}_{2} \mathrm{C}_{1}-\mathrm{C}_{1} \mathrm{C}_{2}$ & press the key of a word (right key) \\
\hline Number & $\begin{array}{l}\text { a Roman numeral (I to VIII) on the left } \\
\text { and an Arabic numeral on the right } \\
\text { ( } 1 \text { to } 8 \text { ) }\end{array}$ & V-7 & $\begin{array}{l}\text { press the key of a larger numeral (right } \\
\text { key) }\end{array}$ \\
\hline
\end{tabular}

Note-For Production Phonetic, Chinese characters contain 3 or 4 strokes only, so that a character and a phonetic symbol are similar in appearance.

among the eight lists constituting a set. For Rule Military, for example, the range and mean of rank differences between military titles within each list were approximately equal. With respect to Rule Animal, two animals of a condition instance were chosen so that there would be no ambiguity for judging which was larger. With eight types of rule, eight one-rule sets were obtained, as is indicated in the last column of Table 2 . For each set, the number of correct right-key presses was made equal to the number of correct left-key presses.

Two-rule sets were constructed by combining two one-rule sets (see the middle column of Table 2) as follows: First, four condition instances were selected randomly from each list of a one-rule set with the restriction that the total number of correct right-key presses be the same as the total number of correct left-key presses. While retaining their original serial positions, the remaining four condition instances were then selected from the complementary positions in each list of another one-rule set. There were four tworule sets. The composition of each two-rule set is indicated in Table 2 . To control for possible serial-position effect within each list, two equivalent forms were constructed for each two-rule set. Similarly, two four-rule sets and one eight-rule set were constructed. Again, there were two equivalent forms of each of these sets.

Design. The design was essentially a $2 \times 4 \times 4$ within-subjects factorial. The first factor refers to whether subjects were required

Table 2

Set of List Materials

\begin{tabular}{clc}
\hline Type of Set & \multicolumn{1}{c}{ Content } & $\begin{array}{c}\text { Number } \\
\text { of Sets }\end{array}$ \\
\hline 1-Production & $\begin{array}{l}\text { Military, Animal, Letter, Order, } \\
\text { Sameness, Phonetic, Word, Number }\end{array}$ & 8 \\
2-Production & $\begin{array}{l}\text { Military-Animal, Letter-Order } \\
\text { Sameness-Phonetic, Word-Number } \\
\text { 4-Production }\end{array}$ & $\begin{array}{l}\text { Military-Animal-Letter-Order, } \\
\text { Sameness-Phonetic-Word-Number }\end{array}$ \\
8-Production & $\begin{array}{l}\text { Military-Animal-Letter-Order- } \\
\text { Sameness-Phonetic-Word-Number }\end{array}$ & 1 \\
\hline
\end{tabular}

Note-Each set contains 8 lists, each list consisting of 8 condition instances. to recall condition instances at the end of a list. The second factor refers to number of rules in a list of eight condition instances. This number was $1,2,4$, or 8 , as represented by one-, two-, four-, or eight-rule sets, respectively. The third factor refers to four stages of practice. The four stages of practice refer to the first, third, fifth, and seventh lists of each set when subjects were not required to recall condition instances, and to the second, fourth, sixth, and eighth lists of each set when subjects were required to recall condition instances.

Apparatus and Procedure. Each list of eight condition instances was drawn on a film strip and presented on a screen by means of a Dukane filmstrip projector. With each n-rule set consisting of eight lists, Figure 1 shows a list from a one-rule set and a list from a two-rule set. A specially designed timing device was connected to the projector in such a way that a frame containing a condition instance was advanced automatically every $4 \mathrm{sec}$. A clock that started simultaneously with each advancement of a frame was stopped by the subject's keypress. Therefore, from each n-rule set, $8 \times 8=64$ RTs could be collected.

Each subject received eight one-rule sets and one form each of four two-rule sets, two four-rule sets, and one eight-rule set. The subject always received one entire set before receiving another set, and always received all sets of one type before receiving a set belonging to another type. The order of assignment of different types of set was counterbalanced between subjects. Also counterbalanced between subjects were (1) forms of two-, four-, and eight-rule sets and (2) order of eight lists within each set.

The subject participated in the experiment for four sessions, each session on a different day. One session lasted about $40 \mathrm{~min}$, during which three (only once) or four sets of lists were administered. Before starting a different type of set, the subject was familiarized with each appropriate rule, with the stimulus terms used, examples of condition instances, and the correct keypress rule being given. Then the subject rested the right index finger on the middle key, which was not depressible, and always returned to the middle key immediately after responding to a condition instance by pressing the right or the left key. The subject was instructed to respond as fast as possible without making an error.

Before the start of every second list, the subject was informed that a recall test would be administered later. Immediately after every second list, the subject was allowed $50 \mathrm{sec}$ for free recall of condi- 
tion instances. Therefore, for each set of eight lists, recall data were collected from the second, fourth, sixth, and eighth lists.

\section{Results}

Reaction times. Since our main interest was in finding the effect of number of rules involved in a list of condition instances, the sets containing the same number of rules were combined (see Table 2). The obtained mean reaction times are presented separately for Lists $1,3,5$, 7 and Lists 2, 4, 6, 8 in Figures 2 and 3. All statistical tests to be reported below are based on a .05 significance level. An analysis of variance showed that number of rules was not a significant source of variance $[\mathrm{F}(3,33)=1.14$, $\mathrm{MSe}=.094]$. The subjects reacted faster with practice $[\mathrm{F}(3,33)=19.89, \mathrm{MSe}=.009] . \mathrm{RT}$ was slower when the subjects were required to recall the condition instances of a list than when not required to recall them $[F(1,11)$ $=16.64, \mathrm{MSe}=.068 \mathrm{]}$, although the subjects received one more list of practice for each of Lists $2,4,6,8$ than for Lists 1, 3, 5, 7. The interaction between practice and recall instruction was significant $[F(3,33)=17.47$, MSe $=.006$, indicating that more improvement in reaction time with practice was generally obtained when the subject was not required to recall than when required to recall the condition instances of a list. The three-way interaction was also significant $[F(9,99)=5.90, \mathrm{MSe}=.004]$. The significant interaction is apparently produced by a U-shaped curve of the 4-rule set and is perhaps due to a chance factor. A general trend seems to be that an initial performance level was resumed whenever the subjects were required to recall condition instances. No other interactions were significant.

Table 3 presents the error rates according to the same classification of the experimental variables of Figures 2 and 3. It is clear that the percentage of errors was quite stable across lists containing different numbers of rules. The percentage of errors was also not changed whether the subject was required to recall the condition instances of a list or not.

Recall. The mean number of condition instances correctly recalled as a function of practice and number of rules contained in a list is shown in Figure 4. An analysis of variance showed that the subjects recalled more condition instances as the number of rules increased $[F(3,33)$ $=4.67, \mathrm{MSe}=2.99]$. As the number of lists to be recalled increased, the number of condition instances correctly recalled decreased, but abruptly increased on the last list $[\mathrm{F}(3,33)=4.65, \mathrm{MSe}=.67]$. The decline in recall apparently reflected a fatigue effect, and the regain on the last list obviously shows the subjects' last

Table 3

Percentage of Errors

\begin{tabular}{cccccccccccc} 
& \multicolumn{4}{c}{ Nonrecall List } & & \multicolumn{4}{c}{ Recall List } \\
\cline { 2 - 5 } \cline { 8 - 10 } Type of Set & 1 & \multicolumn{1}{c}{3} & 5 & 7 & Mean & & 4 & 6 & 8 & Mean \\
\hline 1-Production & 5.0 & 6.1 & 5.1 & 6.0 & 5.6 & 6.9 & 4.1 & 6.9 & 5.5 & 5.9 \\
2-Production & 5.5 & 7.3 & 5.0 & 3.3 & 5.3 & & 4.5 & 5.5 & 6.5 & 4.3 & 5.2 \\
4-Production & 8.5 & 6.0 & 5.5 & 4.0 & 6.0 & & 9.0 & 5.5 & 8.0 & 6.0 & 7.1 \\
8-Production & 7.3 & 11.5 & 3.1 & 4.1 & 6.5 & & 7.3 & 5.2 & 8.3 & 5.2 & 6.5 \\
\hline
\end{tabular}

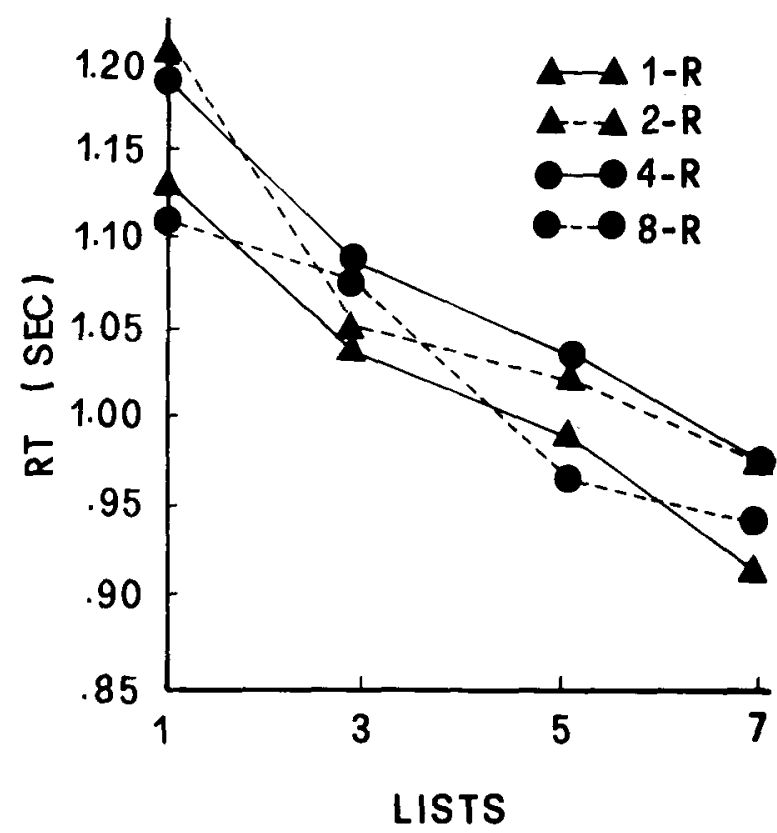

Figure 2. Mean reaction time as a function of practice for onerule (1-R), two-rule (2-R), four-rule (4-R), and eight-rule (8-R) sets, when the subject was not required to recall the lists.

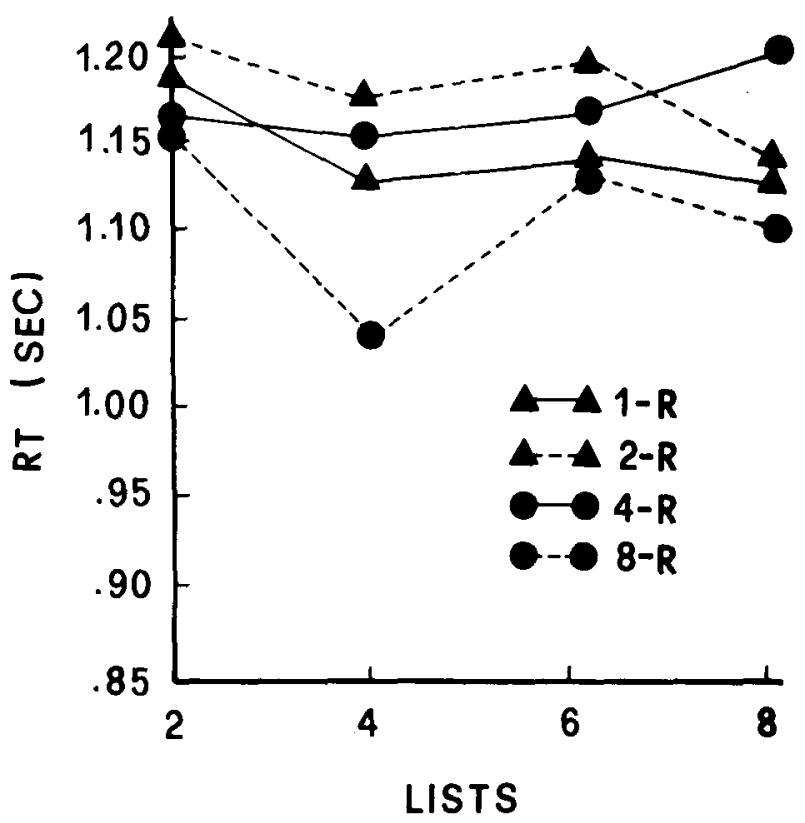

Figure 3. Mean reaction time when the subject was required to recall the lists as a function of practice.

effort because the number of lists to be recalled for each set was known to the subjects. The interaction between number of different rules and practice was not significant $[F(9,99)<1]$.

\section{Discussion}

The obtained RT in the present experiment may be considered to consist of two components: the time required 


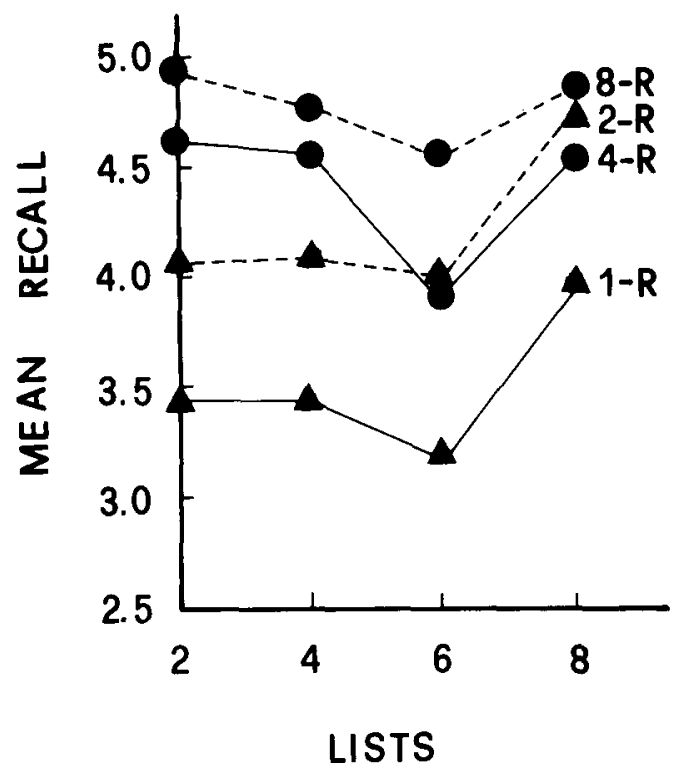

Figure 4. Mean recall for each type of set as a function of practice.

to categorize a condition instance and the time required to translate the result of categorization into the keypress response. With the present procedure, it has been argued that the condition-action translation time is fairly the same among various rules and is independent of the number of rules in a list. The present experiment, then, demonstrated that the time needed to categorize a condition instance is independent of the number of rules present in a list. This means that the relevant condition-action rules are not transferred to a rapid-access storage, because it is generally impossible to hold as many as eight rules in working memory without affecting RT.

A robust finding from choice RT experiments is that RT is linearly related to the amount of stimulus information available (e.g., Hick, 1952; Hyman, 1953; reviews by Smith, 1968, and Teichner \& Krebs, 1974). As pointed out earlier, in these experiments the number of stimuli was not separated from the number of responses. Moreoever, when the stimuli and responses were highly compatible, the slope of the function was generally found to be nearly flat. This is in line with the present finding that condition-categorization time is independent of the number of rules.

A possible explanation for the present results is as follows. When the subject is familiarized with a given number of condition-action rules, each rule is stored with a stimulus category to which condition instances are related. In order to store a rule with the corresponding stimulus category, it is not necessary for the subject to rehearse the rules from time to time because all rules are highly compatible. For example, the rule for pressing the key for a higher military rank parallels the rule for pressing the key of a larger animal, etc. The rule for pressing the key for phonetic symbol is also similar, inasmuch as phonetic symbols differ from usual characters. Therefore, the subject could be responding according to a general rule for pressing the key for some unusual stimulus. Since the subject is not constantly rehearsing them, the given condition-action rules are not transferred to a rapid-access storage system.

When a condition instance is presented, a control process is initiated to assist stimulus encoding and retrieval of the condition-action rule that is stored with the related stimulus category. Without operation of the control process, a presented condition instance is still automatically encoded and the related condition-action rule retrieved. However, operation of the control process is assumed to speed up encoding and retrieval. Operation of the control process is analogous to paying special attention. Since the given set of condition-action rules was not transferred to a rapid-access storage system, the number of rules within a list had no effect on the RT.

It is assumed that the control process is a part of working memory and at the same time capable of making contact with information in long-term memory. Since working memory is limited in capacity, operation of the control process invariably draws resources from working memory. If the subject is required to recall condition instances at the end of each list, he or she will attempt not only to rehearse them constantly but to elaborate on them for their transfer to long-term memory. This will compete with the control process that is engaged in executing the condition-to-action sequence. As Figure 3 shows, when the subject was required to recall condition instances in various stages of training, the subject's attempt to transfer condition instances to long-term memory would draw on available resources so that the improvement in performance at any stage was immediately halted to assume an initial level of performance. The reason for the higher levels of recall for larger numbers of rules may be due to less interference in the latter conditions, because condition instances become more dissimilar as rules within the lists increase.

\section{EXPERIMENT 2}

In Experiment 1, the rule set size effect was not obtained. Although it was reasoned that the absence of this effect is due to the rules' being highly compatible, the procedure of using rules itself may be a possible explanation. Therefore, in Experiment 2, two incompatible rules were used.

Suppose that two condition-action rules are represented by If $A$, then $R$ (an abbreviation for "If $\mathrm{A}_{1}$, then $\mathrm{R}_{1}$; if $\mathrm{A}_{2}$ then $\mathrm{R}_{2}$ ") and If $B$, then $R^{\prime}$ (an abbreviation of "If $B_{1}$, then $R_{2}$; If $B_{2}$, then $R_{1}$ '). Suppose further that the $A-R$ rule is easier to execute (as determined by faster $R T$ ) than the $B-R^{\prime}$ rule. Then there are at least two possible consequences when the A-R and B-R' rules are combined as a two-rule set. First, since the two rules are incompatible, the subject may constantly rehearse the easier A-R rule first and the more difficult $B-R^{\prime}$ rule next. Thus, the execution of the A-R rule would be affected less than the 
$B-R^{\prime}$ rule when the subject performed them in a two-rule set. According to the second possibility, both rules would be equally affected in their condition-to-action translation time because the subject might not necessarily rehearse the easier rule first and the more difficult rule next.

\section{Method \\ Subjects and Materials. The subjects were the same 12 subjects} used in Experiment 1. They were paid for participating in Experiments 2 and 3.

Three sets of six lists each, each list containing eight condition instances, were constructed, as in Experiment 1. Thus, each set of Experiment 2 consisted of $6 \times 8=48$ trials. There were two one-rule sets and one two-rule set. For Rule Roman, a set of six lists was constructed in the same way as a one-rule set for Rule Number in Experiment 1. The only difference was that each condition instance consisted of a pair of Roman numerals. The subject was to respond to a larger numeral, as in Rule Number of Experiment 1. Similarly, one rule set for Rule Arabic was constructed. For this rule, the subject was to respond to the smaller of a pair of Arabic numerals. A two-rule set for Rule Roman and Rule Arabic was obtained as in the construction of a two-rule set in Experiment 1. Finally, all Roman and Arabic numerals were interchanged to obtain two equivalent forms for each of the three sets.

Procedure. The subject received each set of condition instances as in Experiment 1. The one-rule sets were presented first to half the subjects; the two-rule set was presented first to the remaining subjects. Half the subjects received one of two equivalent forms for each set. Also counterbalanced was the order of set assignment in Experiment 2 and Experiment 3, so that the results obtained from Experiments 2 and 3 would be comparable.

After having reacted to a list of eight condition instances, the subject was instructed to write either the larger or the smaller of each pair of numerals within $20 \mathrm{sec}$. If the subject could recall only on which side the larger or the smaller number of a condition instance was located, he or she was to tick that side on a sheet of paper. For half the lists of each set, the subject was asked to write the larger number of each condition instance; for the other half, the subject was to write the smaller number of each condition instance. This assignment was random so that the subject could not anticipate it at the time he or she received a list of condition instances. The subject was warned not to intentionally rehearse the numerals so as to affect reaction time to a condition instance.

\section{Results and Discussion}

Reaction times. The mean reaction time obtained for each type of rule (Rule Roman or Rule Arabic) is shown in Figure 5 for each type of set (1-rule or 2-rule set). The practice effect was not considered because it was very small and almost negligible. An analysis of variance showed that the subjects were faster in executing Rule Arabic than Rule Roman $[\mathrm{F}(1,11)=94.08, \mathrm{MSe}=.005]$. The subjects were also faster in reacting to a condition instance from a one-rule set than to one from a two-rule set $[\mathrm{F}(1,11)=17.06, \mathrm{MSe}=.017]$. The interaction between type of rule and type of set was not significant $[\mathrm{F}(1,11)<1]$.

As Figure 5 shows, in reacting to a condition instance in a list of a two-rule set, the subjects took an additional $150 \mathrm{msec}$ in the condition-to-action translation stage no matter which rule was concerned. This inference is based on the reasoning that the condition-categorization time was equated in responding to one-rule and two-rule sets when the same type of rule was considered.

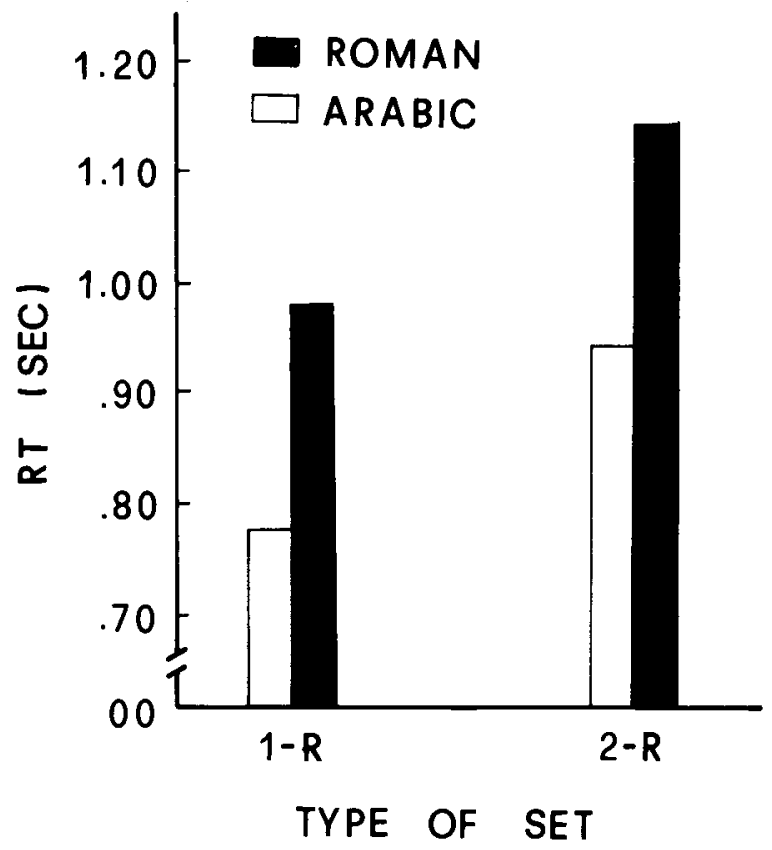

Figure 5. Mean reaction time for Rule Roman and Rule Arabic as a function of type of set.

Furthermore, the subjects took an additional $200 \mathrm{msec}$ to condition-categorize for Rule Roman as compared with Rule Arabic. This additional $200 \mathrm{msec}$ must have been spent on the extraction of meaning and feature comparison of Roman numerals, because Roman numerals are apparently rarely used.

The error rates for Rule Roman and Rule Arabic were $5.73 \%$ and $3.30 \%$, respectively, in the one-rule set and $7.99 \%$ and $9.38 \%$, respectively, in the two-rule set. An analysis of variance showed that the subjects made more errors in the two-rule set than in the one-rule set $[F(1,11)$ $=7.23$, MSe $=6.64]$. This result differs from the pattern of error rates obtained in Experiment 1, and parallels the obtained increase in reaction time for the two-rule set. It is evident that the subjects were more overloaded in reacting to a condition instance in the two-rule set.

Recall. As was originally conceived, the numerals to which the subject reacted might be easier to recall than those not reacted to. Figure 6 shows the mean number of numerals correctly recalled for each rule as a function of whether they were to be reacted to or not. Assignment of subject to recall the larger or the smaller numerals did not interact with type of rule $[F(1,11)<1]$. Remember that the subject was to react to the smaller number for Rule Arabic and to the larger number for Rule Roman. Arabic numerals were recalled more than Roman numerals, irrespective of whether the subject was assigned to recall the larger or the smaller numerals $[F(1,11)=$ 16.79 , MSe $=1.49$ ]. Although not significant, both Arabic and Roman numerals tended to be recalled less in the two-rule set than in the one-rule set $[\mathrm{F}(1,11)=$ 3.99, $\mathrm{MSe}=2.51]$.

Since assignment of the larger or smaller numbers to 


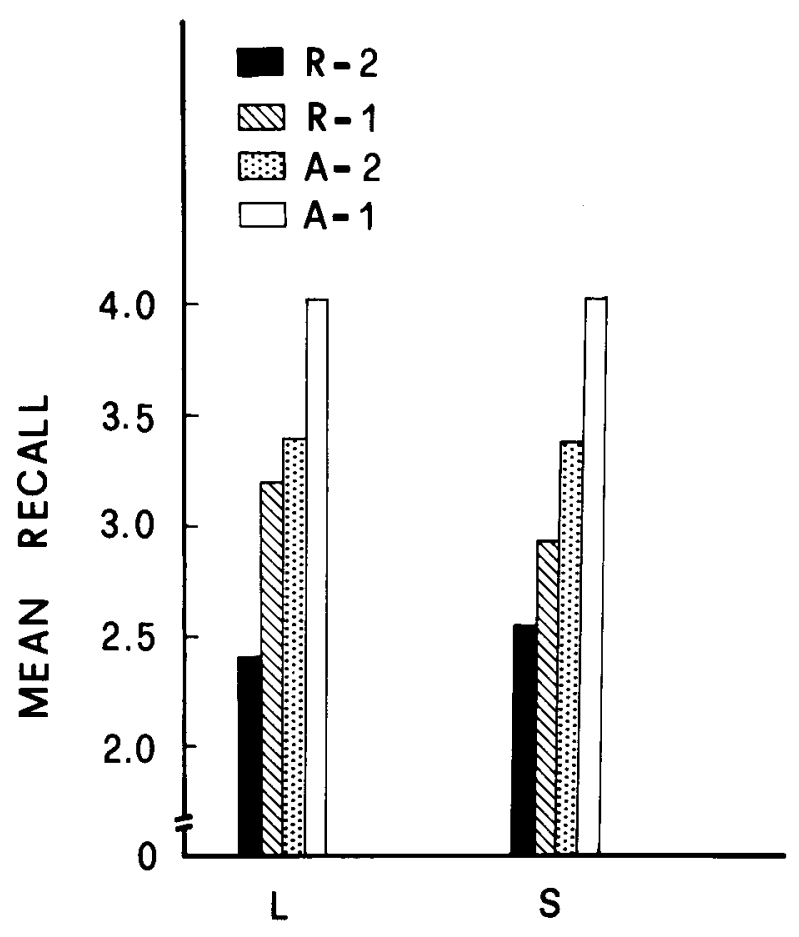

\section{ASSIGNMENT}

Figure 6. Mean recall as affected by whether the subject was assigned to recall the larger (L) or smaller (S) numbers. $A$ and $R$ stand for Rule Arabic and Rule Roman, respectively; 1 and 2 stand for one-rule or two-rule set, respectively.

be recalled did not interact with type of rule, it may be inferred that the subjects were reacting to a condition instance as a whole rather than additionally processing the numeral to be reacted to. The tendency of a lower recall level obtained with the two-production set is inconsistent with the finding of Experiment 1, but is consistent with the observations of the present experiment, in which error rates were greater and reaction times were longer in the two-rule set than in the one-rule set. If the magnitude of the error rates is also taken into account, the additional time taken in reacting to the two-rule set is only underestimated.

\section{EXPERIMENT 3}

In Experiments 1 and 2, each rule is signaled entirely by a condition instance. For instance, when a pair of Roman numerals appeared in Experiment 2, the subject was to respond to a larger numeral because a pair of Roman numerals signaled Rule Roman to be followed. The manipulation of rule compatibility may depend on this characteristic of rules as signaled by condition instances alone. To obtain the generality of the finding of Experiment 2, Experiment 3 was devised in such a way that a rule is signaled by a cue external to condition instances.
In the present experiment, the cues $\mathrm{L}$ (large) and $S$ (small) were used so that a condition instance, L(5-8), signified to the subject that he or she was to press the right key (the key of the larger number). The same condition instance with a different cue, $S(5-8)$, signified to the subject that the left key was to be pressed (the key of the smaller number). These two types of rules will be referred to as Rule $\mathrm{L}$ and Rule $S$, respectively.

When the subject reacts to a condition instance in the two-rule set containing Rules $\mathrm{L}$ and $\mathrm{S}$, he or she must constantly maintain a relevant external cue in working memory to use as a guide in selecting a correct action, because the end product of stimulus categorization is the same for both condition instances. Therefore, the ruleset-size effect would be obtained for these incompatible rules, and it was expected that the subject would be constantly processing the external cue to avoid selecting an incorrect action. This predicted a longer additional reaction time for a condition instance in the two-rule set than was obtained in Experiment 2.

\section{Method}

Materials. A set of six lists, each consisting of eight condition instances, was constructed for Rule $L$ in the same way as it was for Rule Arabic in Experiment 2. The only difference was that a one-character Chinese word meaning large was presented along with each condition instance. If $\mathrm{L}$ is used to stand for this one-character Chinese word, then L(3-7) was used as a condition instance. Similarly, a set of six lists was constructed for Rule S. An example in this case would be $S(3-7)$, $S$ standing for a one-character Chinese word that meant small. A two-rule set for Rule L and Rule $\mathrm{S}$ was similarly constructed as the two-rule set in Experiment 2 . By interchanging $L$ and $S$, two equivalent forms were obtained for each set.

Procedure. The details of the procedure were the same as in Experiment 2 . In the recall test, the experimenter had the subject attempt to recall the larger or smaller number of each condition instance in a list. The recall data will not be reported, because no new information was obtained. As before, half the subjects received the three sets of Experiment 2 first, and the remaining half received the three sets of Experiment 3 first, so that the results of Experiments 2 and 3 were comparable.

\section{Results and Discussion}

Reaction times. The subjects' improvement in the course of processing six lists of condition instances was negligibly small. Therefore, the mean reaction time for each type of rule (Rule L or S) was computed for each type of set (1-rule or 2-rule set). The results are presented in Figure 7. An analysis of variance showed that type of rule was a significant source of variance $[F(1,11)=7.43$, $\mathrm{MSe}=.0017]$. The subjects were faster in reacting to a condition instance from a one-rule set than to one from a two-rule set $[\mathrm{F}(1,11)=64.69, \mathrm{MSe}=.001]$. The interaction between type of rule and type of set was not significant $[F(1,11)<1]$.

The mean reaction time to condition instances in the onerule set for Rule $S$ was $.78 \mathrm{sec}$. This is almost identical to the mean reaction time of $.77 \mathrm{sec}$ for condition instances in the one-rule set for Rule Arabic in Experiment 2. As a matter of fact, Rule $S$ and Rule Arabic are identical so 


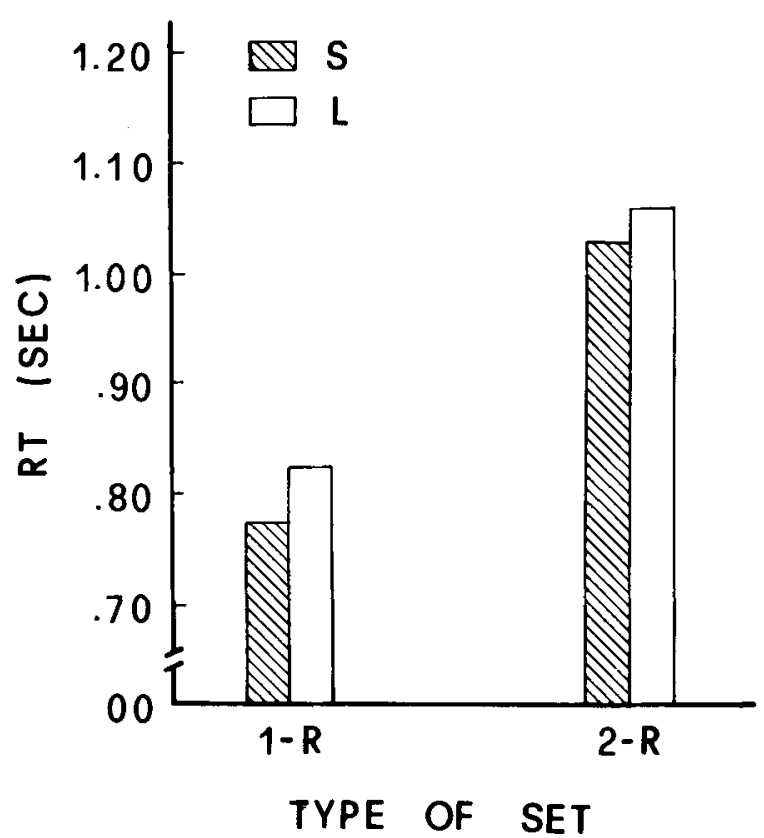

Figure 7. Mean reaction time as a function of type of set for Rule $L$ and Rule S.

long as they are to be executed in a one-rule set, because they all require reaction to the smaller of two Arabic numerals. The cue of $S$ for Rule $S$ in a one-rule set is essentially nonfunctional.

When Rule $\mathrm{S}$ was embedded in a two-rule set, the external cue (S) became functional and the mean reaction time took an extra $250 \mathrm{msec}$ (see Figure 7). According to the argument presented in Experiment 2, this increase in the mean reaction time should occur in the stage of condition-to-action translation. The increase of $250 \mathrm{msec}$ was larger than the increase of $150 \mathrm{msec}$ obtained for Rule Arabic in Experiment 2, as predicted. A statistical test showed that the difference between a 250-msec increase and a 150 -msec increase was significant $[t(11)=2.29]$.

The execution of Rule $\mathrm{L}$ was found to take $30 \mathrm{msec}$ on average, longer than the execution of Rule $S$, regardless of whether a condition instance was embedded in a onerule or a two-rule set (see Figure 7). Since the difference was significant, it has an important meaning. First of all, it should be noted that this 30 -msec interval could not be due to a processing difference in the condition categorization. This is because a condition instance for Rule $\mathrm{L}$ is the same as that for Rule $S$, except for the external cues of large and small. However, large is an unmarked adjective and higher frequency word. Large then is at least identified as fast as small. Therefore, the shortened $30 \mathrm{msec}$ for Rule $\mathrm{S}$ must at least be attributable to the stage of condition-to-action translation. Perhaps, as a consequence of the stage of stimulus categorization, the subject is likely to represent the encoded numerals in the order of small-to-large numbers. This representation is to the advantage of Rule $S$, because in the stage of conditionto-action translation an action is to be assigned to the smaller number rather than to the larger number. A natural implication of the present argument is that the additional 200 msec taken for Rule Roman than for Rule Arabic in Experiment 2 should not be attributable entirely to the stage of condition categorization. Instead, approximately

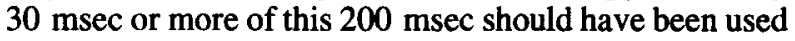
in the later stage of response mapping for Rule Roman.

The error rates for Rules $L$ and $S$ were $7.47 \%$ and $2.95 \%$, respectively, in the one-rule set and $8.68 \%$ and $8.68 \%$, respectively, in the two-rule set. According to an analysis of variance, the subjects made more errors in the two-rule set than in the one-rule set $[\mathrm{F}(1,11)=5.05$, MSe $=6.61]$. As observed in Experiment 2, this trend is consistent with the obtained increase in the reaction times for the two-rule set, and reflects a processing overload in reacting to a condition instance in the two-rule set.

\section{GENERAL DISCUSSION}

In the present study, a condition-action rule is represented by "If $X_{1}$, then $R_{1}$; if $X_{2}$, then $R_{2}$," or simply "If $X$, then $R$." In executing a rule, two stages can be identified. The first is the stage of condition categorization, and the second, the stage of condition-to-action translation. As found in Experiment 1, when the relevant rules were higly compatible, the number of rules had no effect on the time of condition categorization. It was reasoned that this finding was obtained because the response selection was effectively controlled by the present technique. This finding refutes the general assumptions of production system models and also casts doubt about the well-established finding that choice RT is a function of amount of stimulus information. However, the present finding is consistent with the growing evidence that the bottleneck of perceptual processing occurs not early, at the time of stimulus categorization, but quite late, at the stimulus-to-response translation stage. Thus, for highly compatible rules, the stimulus-to-response translation stage can be bypassed. On the other hand, for the incompatible rules of Experiment 2, this stage could not be bypassed and the rule-set-size effect was obtained. Experiment 3 further confirmed that it is rule incompatibility which gives rise to this effect and not the locus of cues for signaling rules.

Apart from the major finding of the present study, it was also found, in Experiment 1, that the subject's improved performance was completely nullified with an assumption of his or her initial performance level whenever he or she was required to recall condition instances. This means that the subject's improved performance was not yet becoming automatic and still competed for limited resources that had to be used in transferring to-be-recalled items to long-term memory.

In Experiment 2, one rule is represented by "If $A_{1}$, then $R_{1}$; if $A_{2}$, then $R_{2}$ " and another by "If $B_{1}$, then $R_{2}$; if $B_{2}$, then $R_{1}$." In this way, it was possible to combine the additive-factor method (Sternberg, 1966) and the component-task method (e.g., Liu \& Kuo, 1968) to study 
the stage of condition-to-action translation separately from the stage of condition categorization. The variable that affects the time of condition categorization (different rules) and the variable that affects the time of condition-to-action translation (one rule vs. two rules) were found to be additive. Thus, the additional time used in the condition-toaction translation as well as the additional time used in the condition categorization for a given rule could be estimated. Because, with the present component-task method, each condition-action rule itself is a choice-RT task, some defects inherent in the Donders subtraction method (Pachella, 1974) can be avoided. Condition-action rules similar to those studied in Experiment 3 prevail in real life. The way a boy greets his father on a street may be different from the way in which he greets him if he meets him in school. A condition instance as exemplified by a boy meeting his father is the same in both cases, but the resultant actions would be different because the external environments were different.

In the literature, Posner (1964) classified the type of the present task as "gating" because it allows the subject to ignore some aspects of the stimulus. He called a task requiring all aspects of the stimulus to be represented in the response in a condensed form "condensation." Archer (1954) and Gregg (1954) have studied the former type of task. In both situations, the subject had to classify one or more binary relevant dimensions while ignoring one or more binary irrelevant dimensions. However, in a single condition, only one rule was involved. Similarly, Crossman (1953) studied card sorting under a number of conditions. One condition involved sorting the cards into two categories. This condition, again, represents a one-rule task of the present experiment. In the other conditions, Crossman increased the number of categories into which the cards had to be sorted. In other words, the number of responses was varied.

A human being acquires and maintains a large number of condition-action rules in his or her life. In the future, the present technique can be used to study sequences of interrelated condition-action rules, generally referred to as scripts (Schank \& Abelson, 1977), and many related problems.

\section{REFERENCES}

ANDERSON, J. R. (1976). Language, memory and thought. Hillsdale, NJ: Erlbaum.

ARCHER, E. J. (1954). Identification of visual pattern as a function of information load. Journal of Experimental Psychology, 48, 313-317.

BadDEley, A. D., \& HrTCH, G. (1974). Working memory. In G. A. Brown (Ed.), The psychology of learning and motivation. New York: Academic Press.

BAYLOR, G. W., \& GASCON, J. (1974). An information processing theory of aspects of the development of weight seriation in children. $\mathrm{Cog}$ nitive Psychology, 6, 1-40.

Chase, W. G., \& Ericsson, K. A. (1981). Skilled memory. In J. R. Anderson (Ed.), Cognitive skills and their acquisition. Hillsdale, NJ: Erlbaum.
Crossman, E. R. F. W. (1953). Entropy and choice time: The effect of frequency unbalance on choice-response. Quarterly Journal of Experimental Psychology, 5, 41-51.

FISK, A. D., \& SchNeIDER, W. (1983). Category and word search: Generalizing searching principles to complex processing. Jourmal of Experimental Psychology: Learning, Memory, and Cognition, 9, 177-195.

Greenwald, A. G. (1972). Time sharing as a function of ideomotor compatibility. Journal of Experimental Psychology, 94, 52-57.

Greenwald, A. G. \& Schulman, H. G. (1973). On doing two things at once: II. Elimination of the psychology refractory period effect. Journal of Experimental Psychology, 101, 70-76.

GREGG, L. W. (1954). The effect of stimulus complexity on discrimination responses. Journal of Experimental Psychology, 48, 289-297.

Hick, W. E. (1952). On the rate of gain of information. Quarterly Journal of Experimental Psychology, 4, 11-26.

Hunt, E. B., \& Poltrock, S. E. (1974). The mechanics of thought. In B. H. Kantowitz (Ed.), Human information processing: Tutorials in performance and cognition. Hillsdale, $\mathrm{NJ}$ : Erlbaum.

Hyman, R. (1953). Stimulus information as a determinant reaction time. Journal of Experimental Psychology, 45, 188-196.

Just, M. A., \& CARPENTER, P. A. (1980). A theory of reading: From eye fixations to comprehension. Psychological Review, 87, 329-534.

KLAHR, D. A. (1973). A production system for counting, subitizing, and adding. In W. G. Chase (Ed.), Visual information processing. New York: Academic Press.

KNEAlE, W., KNEALE, M. (1962). The development of logic. Oxford: The Claredon Press.

Liv, I., \& KUo, S. (1968). Initial improvement in simple reaction time. Journal of Experimental Psychology, 78, 593-598.

NEwELL, A. (1972). A theoretical exploration of mechanisms for coding the stimulus. In A. W. Melton \& E. Martin (Eds.), Coding processes in human memory. Washington, DC: Winston.

NEWELL, A. (1973). Production systems: Models of control structures. In W. G. Chase (Ed.), Visual information processing. New York: Academic Press'.

NewEll, A., \& Simon H. (1972). Human problem solving. Englewood Cliffs, NJ: Prentice-Hall.

Pachella, R. G. (1974). An interpretation of reaction time in information processing research. In B. Kantowitz (Ed.), Human information processing: Tutorials in performance and cognition. Hillsdale, NJ: Erlbaum.

PoSNER, M. I. (1964). Information reduction in the analysis of sequential tasks. Psychological Review, 71, 491-504.

Post, E. L. (1943). Formal reductions of the general combinatorial decision problem. American Journal of Mathematics, 65, 197-268.

RYLE, G. (1949). The concept of mind. London: Hutchinson.

SCHANK, R., \& ABELSON, R. P. (1977). Scripts, plans, goals and understanding. Hillsdale, NJ: Erlbaum.

SCHNEIDER, W., \& SHIFFrIN, R. M. (1977). Controlled and automatic human information processing: I. Detection, search, and attention. Psychological Review, 84, 1-66.

ShIFFrin, R. M. (1975). The locus and role of attention in memory systems. In P. M. A. Rabbit \& S. Dornic (Eds.), Attention and performance $V$. New York: Academic Press.

SMITH, E. E. (1968). Choice reaction time: An analysis of the major theoretical positions. Psychological Bulletin, 69, 77-110.

STERNBERG, S. (1966). High-speed scanning human memory. Science, $153,652-654$.

TeichNer, W. H., \& KREBS, M. J. (1974). Laws of the simple visual reaction time. Psychological Review, 81, 75-98.

WELFORD, A. T. (1960). The measurement of sensory-motor performance: Survey and reappraisal of twelve years' progress. Ergonomics, 3, 189-229.

(Manuscript received March 22, 1984; revision accepted for publication November 6,1984 .) 